\title{
Exploring the electronic, optical and charge transfer properties of acene-based organic semiconductor materials
}

\author{
AHMAD IRFAN ${ }^{1, *} \mathbb{D}$, ABDULLAH G AL-SEHEMI ${ }^{1}$, MOHAMMED A ASSIRI ${ }^{1}$ \\ and MUHAMMAD WASEEM MUMTAZ ${ }^{2}$ \\ ${ }^{1}$ Department of Chemistry, Faculty of Science, King Khalid University, P.O. Box 9004, Abha 61413, Saudi Arabia \\ ${ }^{2}$ Department of Chemistry, University of Gujrat, Gujrat, Punjab 50700, Pakistan \\ *Author for correspondence (irfaahmad@gmail.com)
}

MS received 9 October 2018; accepted 20 December 2018; published online 8 May 2019

\begin{abstract}
In order to tune the optoelectronic and charge transfer properties of 4,6-di(thiophen-2-yl)pyrimidine (1), some new compounds were designed, i.e., 4,6-bis(benzo[b]thiophen-2-yl)pyrimidine (2), 4,6-bis(naphtho[2,3-b]thiophen-2yl)pyrimidine (3), 4,6-bis(anthra[2,3-b]thiophen-2-yl)pyrimidine (4), 4,6-bis(tetraceno[2,3-b]thiophen-2-yl)pyrimidine (5) and 4,6-bis(pentaceno[2,3-b]thiophen-2-yl)pyrimidine (6). Compounds 2-6 were designed by assimilation of benzene, naphthalene, anthracene, tetracene and pentacene, respectively at both ends of compound $\mathbf{1}$. Integration of oligocene end cores reduces the energy gap resulting in a red shift in the absorption and fluorescence emission spectra. The legible intra-molecular charge transfer is significant from electron-rich moieties to the electron-deficient core (pyrimidine). The elongation of $\pi$ conjugation led to escalate the electron affinity, lower the ionization potential and hole reorganization energy. The hole reorganization energies of compounds 3-6 exposed that these materials would be effective hole transport contenders to be used in diverse semiconductor devices.
\end{abstract}

Keywords. Organic thin film transistors (OTFTs); oligothiophenes; electron-deficient core; electro-optical properties; charge transfer.

\section{Introduction}

Recently, molecular electronics have gained increased interest especially in research and development of organic semiconductors which are being expected as new low-cost, flexible, lightweight, environment friendly, versatile and green approach in nature [1-8]. Organic semiconductors can be installed on several large area substrates at large scale production by decreasing manufacturing costs. The development of organic semiconductor materials (OSMs) is being under consideration for multifunctional purposes as organic light-emitting diodes, organic thin film transistors (OTFTs), photovoltaics, photodiodes etc. [9-21]. Due to variable quantity of OSMs, it is possible to modify at the molecular level. The design of specific materials with the desired energy gap, absorption and emission wavelengths is also conceivable. In OTFTs, the mobility is an important parameter which has already improved over the past ten years that is comparable to amorphous silicon. The organic $\pi$-conjugated materials especially acene-based molecules have significant research interest because of their prospective applications in OTFTs and OFETs. Now, the enduring determination is to enhance the carrier mobility of organic materials [21-23].

The first OTFT device was fabricated by polythiophene [24] and then in 1989 a small organic $\pi$-conjugated material, i.e., sexithiophene was used [25]. Since two decades a lot of efforts has been emphasized on the thiophene and oligocenebased compounds to tune the optoelectronic and charge transport properties [26-31]. Additionally, oligothiophenes are also potential candidates for OTFT devices [32]. Hitherto, an electron transfer rate and efficiency have been improved by incorporating the electron-deficient moiety (pyrimidine) between the electron rich units [33,34].

Previously, functional properties of 4,6-di(thiophen-2-yl) pyrimidine (1) were tuned by strengthening the electron rich moieties, i.e., benzothiophene, naphthothiophene and anthrathiophene in 4,6-bis(benzo[b]thiophen-2-yl)pyrimidine (2), 4,6-bis(naphtho[2,3-b]thiophen-2-yl)pyrimidine (3) and 4,6bis(anthra[2,3-b]thiophen-2-yl)pyrimidine (4) [35]. In the present study, two more derivatives have been designed, i.e., 4,6-bis(tetraceno[2,3-b]thiophen-2-yl)pyrimidine (5) and 4,6-bis(pentaceno[2,3-b]thiophen-2-yl)pyrimidine (6) by incorporating the electron-deficient core (pyrimidine) in between tetracenothiophene and pentacenothiophene, respectively. Then various properties of interest were discussed and compared with the parent compound and its derivatives.

Among quantum chemical methods especially, density functional theory (DFT) is a good way to rationalize the experimental data of known materials and to predict the geometries, electronic, optical and charge transfer properties [36,37]. The effect of oligocene substituents was examined on the highest 
<smiles>c1csc(-c2cc(-c3cccs3)ncn2)c1</smiles><smiles>c1ccc2sc(-c3cc(-c4cc5ccccc5s4)ncn3)cc2c1</smiles><smiles>c1ccc2cc3sc(-c4cc(-c5cc6cc7ccccc7cc6s5)ncn4)cc3cc2c1</smiles>

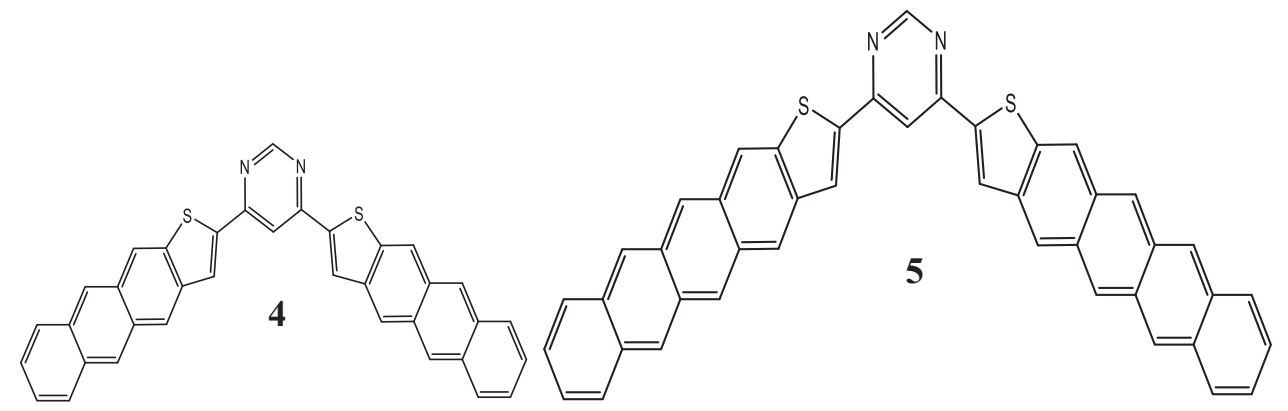<smiles></smiles>

Figure 1. The structures of DTP and its derivatives investigated in the presented study.

occupied molecular orbital energies $\left(E_{\mathrm{HOMO}}\right)$, the lowest unoccupied molecular orbital energies $\left(E_{\mathrm{LUMO}}\right)$, the energy gap ( $E_{\mathrm{g}}$; the difference between the $E_{\mathrm{HOMO}}$ and $\left.E_{\mathrm{LUMO}}\right)$, absorption spectra $\left(\lambda_{\mathrm{abs}}\right)$, fluorescence emission spectra $\left(\lambda_{\mathrm{f}}\right)$, charge transport parameters, e.g., vertical/adiabatic ionization potentials $\left(\mathrm{IP}_{\mathrm{v} / \mathrm{a}}\right)$, vertical/adiabatic electron affinities $\left(\mathrm{EA}_{\mathrm{v} / \mathrm{a}}\right)$ and hole/electron reorganization energies $\left(\lambda_{\mathrm{h} / \mathrm{e}}\right)$ and then compared with some reference compounds. The worthwhile information might shed some light towards the design of further multifunctional OTFT materials, see figure 1.

\section{Methodology}

Previously, it has been found that upon ionization B3LYP [38,39] of DFT [35,40-44] gave the best geometries as compared to other functionals [45]. Also, the experimental geometries were reproduced by DFT at the B3LYP [46] and 6-31G** basis set [47]. In the current study, the ground state $\left(\mathrm{S}_{0}\right)$ geometries of the neutral, anion and cation were optimized at the B3LYP/6-31G** level. The frequency calculations were performed at the same level to see the global minima. Any imaginary frequency was found revealing that the optimized geometries are the stable ones with the lowest energy. The excited state $\left(\mathrm{S}_{1}\right)$ geometries were optimized at time-domain DFT (TDDFT) [48] at the TD-B3LYP/6-31G** level. The energies of the frontier molecular orbitals at $\mathrm{S}_{1}$ were computed from the optimized geometries at the TDB3LYP/6-31G** level. Moreover, the TDDFT was proven to be an efficient approach to reproduce the experimental $\lambda_{\text {abs }}$ and $\lambda_{\mathrm{f}}$ [49]. The $\lambda_{\mathrm{abs}}$ and $\lambda_{\mathrm{f}}$ of the parent molecule (1) at the TD-B3LYP/6-31G** level were observed at 327 and $353 \mathrm{~nm}$ which are in good agreement with the experimental data, i.e., 329 and $378 \mathrm{~nm}$ respectively [50]. The $\lambda_{\text {abs }}$ and $\lambda_{\mathrm{f}}$ were calculated by applying the same level [51]. According to the Marcus theory, the charge transfer rate can be defined as [52]:

$$
W=V^{2} / h\left(\pi / \lambda k_{\mathrm{B}} T\right)^{1 / 2} \exp \left(-\lambda / 4 k_{\mathrm{B}} T\right),
$$

where primary parameters are transfer integral $(V)$ and reorganization energy $(\lambda)$; the first term needs to be maximized while the second one to be small for significant transport. The $\lambda$ can be distributed into two terms, i.e., $\lambda_{\text {rel }}^{(1)}$ and $\lambda_{\text {rel }}^{(2)}$. $\lambda_{\text {rel }}^{(1)}$ and $\lambda_{\text {rel }}^{(2)}$ are the energies of the geometry relaxation from the neutral to charged state and vice versa, respectively [53]. 


$$
\lambda=\lambda_{\text {rel }}^{(1)}+\lambda_{\text {rel }}^{(2)}
$$

In the present study, the $\lambda$ was calculated as [54]:

$$
\begin{aligned}
\lambda= & \lambda_{\text {rel }}^{(1)}+\lambda_{\text {rel }}^{(2)} \\
= & {\left[E^{(1)}\left(V^{+/-}\right)-E^{(0)}\left(V^{+/-}\right)\right] } \\
& +\left[E^{(1)}(V)-E^{(0)}(V)\right] .
\end{aligned}
$$

Here, $E^{(0)}(V)$ and $E^{(0)}\left(V^{+/-}\right)$are the energies $\left(\mathrm{S}_{0}\right)$ of the neutral and charged states, $E^{(1)}(V)$ is the energy of the neutral at the optimized charged geometry and $E^{(1)}\left(V^{+/-}\right)$is the energy of the charged state at the optimized neutral geometry. The $\mathrm{IP}_{\mathrm{a} / \mathrm{v}}$ and $\mathrm{EA}_{\mathrm{a} / \mathrm{v}}$ were calculated at the B3LYP/6-31G** level. The calculations were executed by the Gaussian 16 package [55].

\section{Results and discussion}

\subsection{Electronic properties}

The calculated $E_{\mathrm{HOMO}}, E_{\mathrm{LUMO}}$ and $E_{\mathrm{g}}$ at $\mathrm{S}_{0}$ and $\mathrm{S}_{1}$ compounds (1-6) are illustrated in figure 2 . The computed $E_{\mathrm{HOMO}}$ and $E_{\mathrm{LUMO}}$ are: $\mathbf{1}(-6.19,-1.94), 2$ (-5.95, -2.16), 3 $(-5.46,-2.34), 4(-5.08,-2.50), 5(-4.79,-2.64)$ and 6 $(-4.58,-2.78) \mathrm{eV}$, whereas the trend for $E_{\mathrm{g}}$ is $\mathbf{1}(4.25)>$ $\mathbf{2}(3.79)>\mathbf{3}(3.12)>\mathbf{4}(2.58)>\mathbf{5}(2.15)>\mathbf{6}(1.80) \mathrm{eV}$. It can be seen from figure 2 that by elongating the $\pi$-bridge usually $E_{\text {HOMO }}$ increased while $E_{\mathrm{LUMO}}$ decreased. The work function $(\phi)$ of $\mathrm{Al}$ is $4.08 \mathrm{eV}$ [56]. The electron/hole injection energies for $\mathbf{1}$ are around $(2.14 \mathrm{eV}=-1.94-(-4.08))$ / $(2.11 \mathrm{eV}=-4.08-(-6.19))$. Here $-4.08,-1.94$ and -6.19 $\mathrm{eV}$ are for $\phi$ of Al, LUMO and HOMO of DTP. The $\phi$ of gold (Au) is $5.1 \mathrm{eV}$ and electron/hole injection energies for $\mathbf{1}$ are $(3.16 \mathrm{eV}=-1.94-(-5.10)) /(1.09 \mathrm{eV}=-5.10-(-6.19))$. Thus by depressing/rising the $E_{\mathrm{LUMO}} / E_{\mathrm{HOMO}}$ level it would be gentle to obtain better electron/hole injection strength. The extension of oligocenes declines the electron injection barrier from $\mathrm{Al} / \mathrm{Au}$ as 2 (1.48/2.50), 3 (1.74/2.76), 4 (1.58/2.60), 5 (1.44/2.46) and $6(1.30 / 2.32)$. The hole injection barrier decreases from $\mathbf{1}$ to $\mathbf{6}$ as the $\pi$-bridge expanded. The hole injection barrier from Al/Au 2-6 is 1.87/0.85, 1.38/0.36, $1.00,0.71$ and $0.50 \mathrm{eV}$, respectively. It is accounted from the $E_{\mathrm{LUMO}} / E_{\mathrm{HOMO}}$ levels that the injection barrier would be reduced for the electron/hole which is revealing that by elongating the bridge efficient contenders as the electron/hole transport would be expected.

Similarly, the trend for $E_{\mathrm{g}}$ at $\mathrm{S}_{1}$ has been found as $\mathbf{1}$ (3.92) $>\mathbf{2}(3.46)>\mathbf{3}(2.89)>\mathbf{4}(2.38)>\mathbf{5}(1.91)>\mathbf{6}(1.64) \mathrm{eV}$. It was detected that the $E_{\mathrm{g}}$ decreased by elongating the $\pi$-bridge from benzene to pentacene, see figure 2 . At $S_{0}$ and $S_{1}$, the formation of the HOMO charge density has been delocalized on thiophene, benzothiophene, naphthothiophene, anthracenothiophene, tetracenothiophene and pentacenothiophene
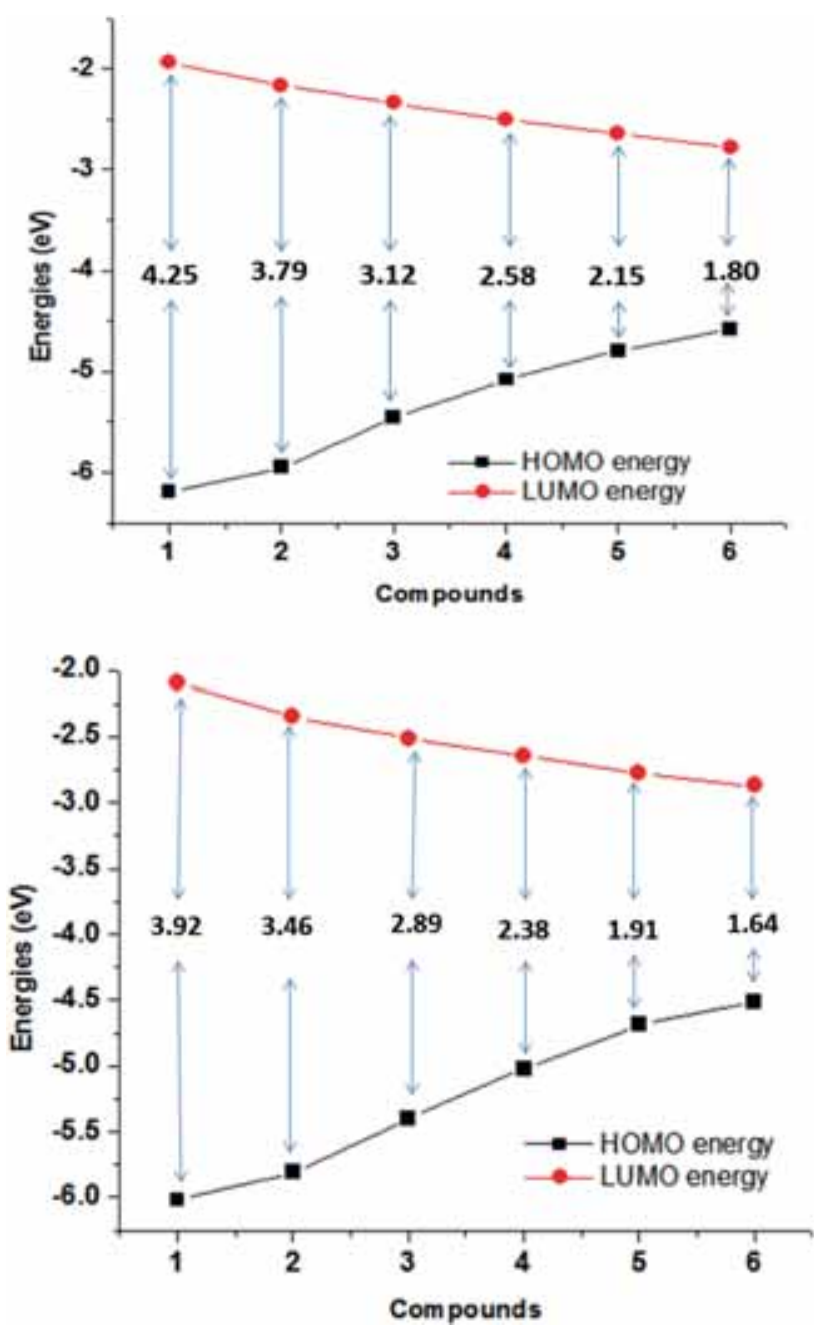

Figure 2. HOMO energies, LUMO energies and HOMO-LUMO energy gaps at ground states (top) and excited states (bottom).

in 1-6, respectively. The LUMO is distributed on whole of the system. An intra-molecular charge transport has been observed from side moieties to the pyrimidine units (figure 3 ).

\subsection{Photophysical properties}

The computed $\lambda_{\mathrm{abs}}, \lambda_{\mathrm{f}}$, oscillator strengths $(f)$ and dominant transitions at the TD-B3LYP/6-31G** level are illustrated in figure 4 . The $\lambda_{\mathrm{abs}}$ and $\lambda_{\mathrm{f}}$ of the parent molecule at the TDB3LYP/6-31G** level of theory have been observed at 327 and $353 \mathrm{~nm}$ which are in good agreement with the experimental data, i.e., 329 and $378 \mathrm{~nm}$ respectively [50]. The considerable transitions are $\mathrm{H} \rightarrow \mathrm{L}$ and $\mathrm{L} \rightarrow \mathrm{H}$ for the absorption and emission, respectively. Additionally, the second peak for the $\lambda_{\mathrm{abs}}$ and $\lambda_{\mathrm{f}}$ has been noticed at 280 and $292 \mathrm{~nm}$ with the transitions from $\mathrm{H}-1 \rightarrow \mathrm{L}+1$ and $\mathrm{L} \rightarrow \mathrm{H}-1$, respectively. By introducing benzene at both the end cores the $\lambda_{\mathrm{a}}$ and $\lambda_{\mathrm{f}}$ are being red shifted, i.e., 40 and $44 \mathrm{~nm}$ in 2 with the main transitions from $\mathrm{H} \rightarrow \mathrm{L}$ and $\mathrm{L} \rightarrow \mathrm{H}$, respectively compared to 

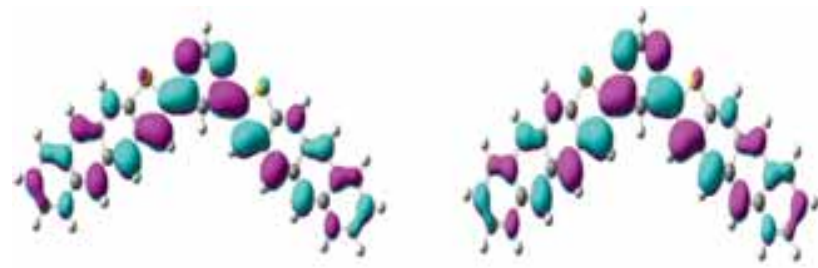

\section{LUMO}
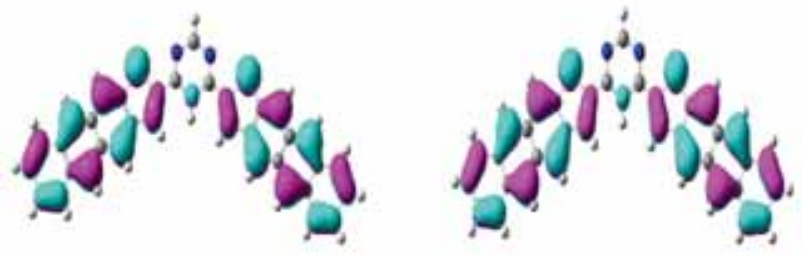

\section{HOMO}

Figure 3. Distribution pattern of the HOMOs and LUMOs of the representative compound (4) at the ground state (left) and excited state (right).

the parent molecule (1). Naphthalene at both the ends lead the $\lambda_{\mathrm{a}}$ and $\lambda_{\mathrm{f}}$ towards the red shift, i.e., 123 and $134 \mathrm{~nm}$ in $\mathbf{3}$ with the transitions from $\mathrm{H} \rightarrow \mathrm{L}$ and $\mathrm{L} \rightarrow \mathrm{H}$, respectively compared to $\mathbf{1}$. Another peak has also been observed in $\mathbf{3}$ which is being 28 and $16 \mathrm{~nm}$ red shifted than the parent molecule with the transitions from $\mathrm{H}-2 \rightarrow \mathrm{L}$ and $\mathrm{L} \rightarrow \mathrm{H}-2$, respectively.

The fusion of anthracene at both the ends also led the $\lambda_{\mathrm{a}}$ and $\lambda_{\mathrm{f}}$ towards the red shift, i.e., 220 and $241 \mathrm{~nm}$ in 4 with the transitions from $\mathrm{H} \rightarrow \mathrm{L}$ and $\mathrm{L} \rightarrow \mathrm{H}$, respectively compared to 1 . The second peak has been detected that is being 43 and $31 \mathrm{~nm}$ red shifted compared to 1 with the transitions from $\mathrm{H}-2 \rightarrow \mathrm{L}$ and $\mathrm{L} \rightarrow \mathrm{H}-2$, respectively. The addition of tetracene at the both ends of the parent molecule resulted in the red shift in the $\lambda_{\mathrm{a}}$ and $\lambda_{\mathrm{f}}$, i.e., 337 and $336 \mathrm{~nm}$ in $\mathbf{5}$ with the transitions from $\mathrm{H} \rightarrow \mathrm{L}$ and $\mathrm{L} \rightarrow \mathrm{H}-1$, respectively compared to 1 . The second peak has been noticed that is being 93 and $79 \mathrm{~nm}$ red shifted compared to 1 with the transitions from $\mathrm{H}-2 \rightarrow \mathrm{L}$ and $\mathrm{L}+3 \rightarrow \mathrm{H}$, respectively. The introduction of pentacene at the both ends of the parent molecule ensured a red shift in the $\lambda_{\mathrm{a}}$ and $\lambda_{\mathrm{f}}$, i.e., 468 and $467 \mathrm{~nm}$ in $\mathbf{6}$ with the transitions from $\mathrm{H} \rightarrow \mathrm{L}$ and $\mathrm{L} \rightarrow \mathrm{H}-1$, respectively compared to 1 . The second peak has been discerned which is being 222 and $227 \mathrm{~nm}$ red shifted compared to 1 with the transitions from $\mathrm{H} \rightarrow \mathrm{L}+2$ and $\mathrm{L}+2 \rightarrow \mathrm{H}$, respectively.

\subsection{Charge transport properties}

To understand the charge transport abilities of the organic compounds IP and EA play a significant role. Usually, higher EA and lower IP would lead to the higher electron and hole transport, respectively. In the present study, we have computed the $\mathrm{IP}_{\mathrm{a} / \mathrm{v}}$ and $\mathrm{EA}_{\mathrm{a} / \mathrm{v}}$ of all the compounds 1-6 at the B3LYP/6-31G** level and shown in figure 5. The $\operatorname{IP}_{\mathrm{a}}\left(\mathrm{IP}_{\mathrm{v}}\right)$ values of 2-6 are 0.44 (0.48), 1.08 (1.14), 1.58 (1.65), 1.95 (2.02) and 2.23 (2.31) eV smaller than those of the parent compound, respectively. The $\mathrm{EA}_{\mathrm{a}}\left(\mathrm{EA}_{\mathrm{v}}\right)$ values of $\mathbf{2 - 6}$ are 0.43 (0.43), 0.75 (0.77), $1.02(1.06), 1.27(1.33)$ and $1.49(1.56) \mathrm{eV}$ larger than those of the parent molecule, respectively. Here, it can be found that by elongating the $\pi$-conjugation at both the ends of 1, IP is being small while EA larger than the parent molecule. This observation revealed that it would lower the charge injection barrier for the hole and electron in new designed derivatives $\mathbf{2 - \mathbf { 6 }}$ resulting in improving the hole and electron charge injection ability than the parent molecule.

There is another imperative parameter which help in comprehending the capability of a compound to transport the charge in solid, i.e., reorganization energy $(\lambda)[54,57]$. Here,

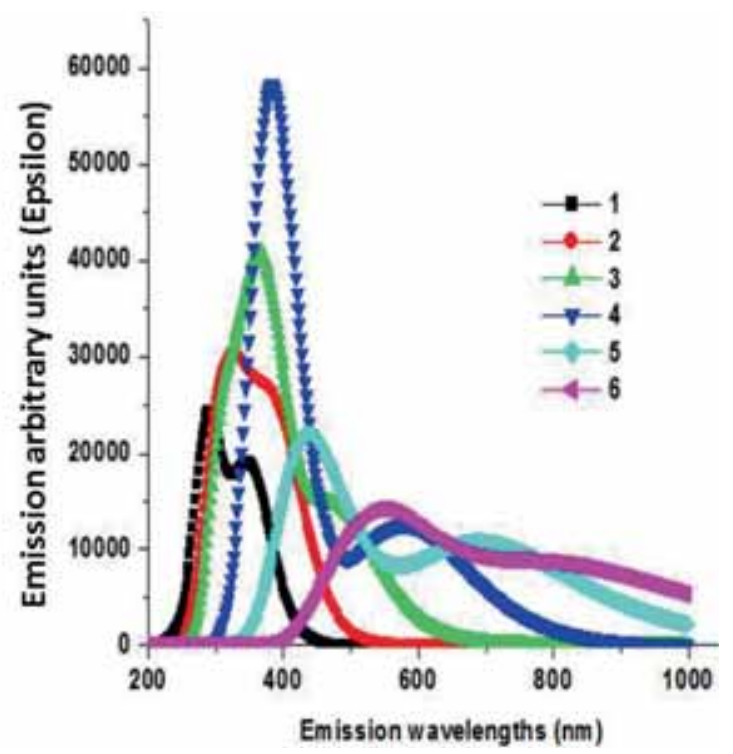

Figure 4. The absorption (left) and fluorescence emission spectra (right) of DTP and its derivatives. 

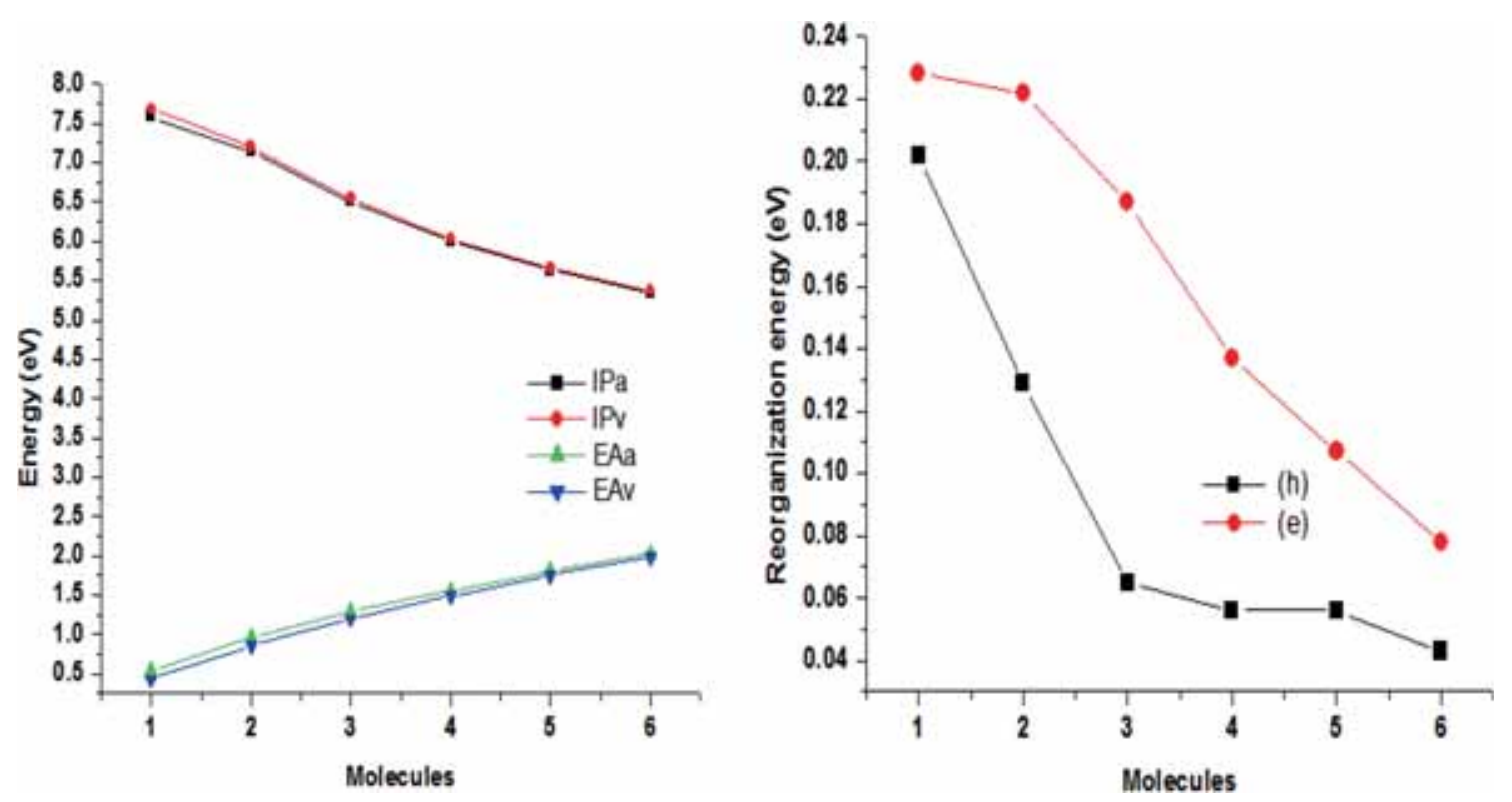

Figure 5. Graphical representation of $\mathrm{IP}_{\mathrm{v}}, \mathrm{IP}_{\mathrm{a}}, \mathrm{EA}_{\mathrm{v}}$ and EA $\mathrm{a}$ (left) while $\lambda(\mathrm{h})$ and $\lambda(\mathrm{e})$ (right) calculated at the B3LYP/6$31 \mathrm{G} * *$ level of theory.

the hole and electron reorganization energies $(\lambda(\mathrm{h})$ and $\lambda(\mathrm{e}))$ have been calculated at the B3LYP/6-31G** level and are shown in figure 5. The fusion of benzene, naphthalene, anthracene, tetracene and pentacene at both the ends of the parent molecule significantly lower the $\lambda(\mathrm{h})$ and $\lambda(\mathrm{e})$. The $\lambda(\mathrm{h})$ and $\lambda(\mathrm{e})$ of all the newly designed derivatives have been compared with distinguished referenced compounds to understand the charge transport performance. The computed values of $\lambda(\mathrm{h})$ of $\mathbf{2 - 6}$ are $0.073,0.137$, $0.146,0.146$ and $0.159 \mathrm{eV}$ smaller than those of the parent molecule, respectively revealing that by elongating the $\pi$-bridge would lead to enhance the hole transport properties. However, the $\lambda(\mathrm{e})$ values of $\mathbf{2 - 6}$ are $0.006,0.041$, $0.091,0.121$ and $0.150 \mathrm{eV}$ smaller than those of the parent molecule, respectively illuminating that by extending the $\pi$ bridge would lead to boost up the electron transport properties. Additionally, the computed $\lambda(\mathrm{h})$ values of 1-6 are smaller than the $\lambda(\mathrm{e})$ enlightening that all the studied compounds might be better hole transport materials than the electron ones.

The $\lambda(\mathrm{h})$ of benzo[1,2-b:5,4- $\left.b^{0}\right]$ dithiophene, naphtho[2, $\left.3-b: 6,7-b^{0}\right]$ dithiophene, naphtho[2,3-b:7,6- $\left.b^{0}\right]$ dithiophene, anthra[2,3- $\left.b: 7,8-b^{0}\right]$ dithiophene, anthra[2,3- $\left.b: 8,7-b^{0}\right]$ dithiophene, thieno[2,3- $\left.f: 5,4-f^{0}\right]$ bis[1]benzothiophene and thieno[3,2- $\left.f: 4,5-f^{0}\right]$ bis[1] benzothiophene are $0.108,0.106$, $0.100,0.096,0.094,0.118$ and $0.146 \mathrm{eV}$ [58]. The $\lambda(\mathrm{h})$ of $\mathbf{3}$ is $43,41,35,31,29,53,81 ; \mathbf{4}$ and $\mathbf{5}$ are $52,50,44,40,38,62$ and $90 ; 6$ is $65,63,57,53,51,75$ and $103 \mathrm{meV}$ smaller than the $\lambda(\mathrm{h})$ of benzo[1,2- $\left.b: 5,4-b^{0}\right]$ dithiophene, naphtho[2,3-b:6, 7- $\left.b^{0}\right]$ dithiophene, naphtho[2,3-b:7,6- $\left.b^{0}\right]$ dithiophene, anthra $\left[2,3-b: 7,8-b^{0}\right]$ dithiophene, anthra[2,3-b:8,7- $\left.b^{0}\right]$ dithiophene, thieno[2,3- $\left.f: 5,4-f^{0}\right]$ bis[1] benzothiophene and thieno[3,2$f: 4,5-f^{0}$ ] bis[1]benzothiophene, respectively [58]. Pentacene is an efficient hole transport material which is being used in OTFT devices. Gruhn et al [59] concluded that the reorganization energy is the important parameter which allows pentacene to prove the predominantly greater mobility. Previously, the $\lambda(\mathrm{h}$ ) of pentacene was calculated to be $0.098 \mathrm{eV}$ [60]. It can be seen from figure 5 that the $\lambda(\mathrm{h})$ values of $3-6$ are $33,42,42$ and $55 \mathrm{meV}$ smaller than those of the referenced compound, i.e., pentacene, respectively showing that these new designed materials might be good/commensurate hole transfer contenders to pentacene. Furthermore, the computed $\lambda(\mathrm{e})$ of a renowned and frequently used electron transfer material meridional-tris(8-hydroxyquinolinato)aluminium (merAlq3) is $0.276 \mathrm{eV}$ [61]. We found that the $\lambda(\mathrm{e})$ values of $\mathbf{1}-\mathbf{6}$ are 48, 54, 89, 139, 169 and $198 \mathrm{meV}$ smaller than mer-Alq3 specifying that electron mobility of these studied compounds 1-6 might be better/corresponding to mer-Alq3 .

\section{Conclusions}

The incorporation of elongated $\pi$-bridge increased the HOMO energy while decreased the LUMO energy values. The electron and hole injection barrier decrease as $\mathbf{2}>\mathbf{3}>\mathbf{4}>\mathbf{5}>\mathbf{6}$. The energy gap is also decreased by elongating the $\pi$-bridge from benzene to pentacene. An intra-molecular charge transport was observed from the oligocene to pyrimidine moiety. By introducing the oligocene units at both the ends of DTP leads to a red shift in the absorption and fluorescence. The fusion of oligocene at the end cores leads to reduction in the IP and an increase in the EA values resulting in the development of hole and electron charge injection ability as compared to the parent compound. The incorporation of benzene, naphthalene, anthracene, tetracene and pentacene at both the ends 
of DTP considerably lower the hole and electron reorganization energies as well. Based on the reorganization energy, it seems that studied compounds might be better hole transport materials. The hole reorganization energies of compounds 3-6 are 33, 42, 42 and $55 \mathrm{meV}$ smaller than those of pentacene, respectively displaying that prior derivatives might be good/comparable hole transport contenders to pentacene. The electron reorganization energy values of $\mathbf{1 - 6}$ are 48, 54, 89, 139, 169 and $198 \mathrm{meV}$ smaller than those of mer-Alq3 illuminating that electron mobility of compounds 1-6 might be better/comparable to mer-Alq3.

\section{Acknowledgements}

The authors extend their appreciation to the Deanship of Scientific Research at King Khalid University for funding this work through research groups program under grant number R.G.P.1/18/40.

\section{References}

[1] Reimers J R, Picconnatto C A, Ellenbogen J C and Shashidhar R 2003 Molecular electronics IH (New York Academy of Science) $\mathbf{1 0 0 6}$

[2] Wazzan N and Irfan A 2018 Org. Electron. 63328

[3] Wazzan N, El-Shishtawy R M and Irfan A 2017 Theor. Chem. Acc. 1379

[4] Habib M, Ghosh N N, Sarkar R, Pramanik A, Sarkar P and Pal S 2018 Chem. Phys. Lett. 70921

[5] Pramanik A, Sarkar S, Pal S and Sarkar P 2015 Phys. Lett. A 3791036

[6] Bouit P-A, Infantes L, Calbo J, Viruela R, Ortí E, Delgado J L et al 2013 Org. Lett. 154166

[7] Habib M, Saha S, Sarkar R, Pramanik A, Sarkar P and Pal S 2018 Comput. Theor. Chem. 1136-1137 10

[8] Roy P, Biswas S, Pramanik A and Sarkar P 2018 Chem. Phys. Lett. 70887

[9] Irfan A, Muhammad S, Al-Sehemi A G, Al-Assiri M S, Kalam A and Chaudhry A R 2015 J. Theor. Comput. Chem. 14 1550027

[10] Irfan A, Al-Sehemi A G and Al-Assiri M S 2014 Comput. Theor. Chem. 103176

[11] Şengez B, Doğruyol Z, San S E, Kösemen A, Yılmaz F, Okutan M et al 2013 Microelectron. Eng. 103111

[12] Szlachcic P, Danel K S, Gryl M, Stadnicka K, Usatenko Z, Nosidlak N et al 2015 Dyes Pigm. 114184

[13] Jungsuttiwong S, Tarsang R, Surakhot Y, Khunchalee J, Sudyoadsuk T, Promarak V et al 2012 Org. Electron. 131836

[14] Marks T J and Hersam M C 2015 Nature 520631

[15] Arunkumar A, Prakasam M and Anbarasan P M 2017 Bull. Mater. Sci. 401389

[16] Ghosh N N, Habib M, Pramanik A, Sarkar P and Pal S 2018 Bull. Mater. Sci. 4156

[17] Kumar M S, Charanadhar N, Srikanth V V S S, Rao K B S and Raj B 2018 Bull. Mater. Sci. 4162

[18] Wang D, Huang S, Wang C, Yue Y and Zhang Q 2019 Org. Electron. 64216
[19] Li M, Kou L, Diao L, Zhang Q, Li Z, Wu Q et al 2015 J. Phys. Chem. A 1193299

[20] Biswas S, Pramanik A, Pal S and Sarkar P 2017 J. Phys. Chem. C 1212574

[21] Tarsang R, Promarak V, Sudyoadsuk T, Namuangruk S, Kungwan N, Khongpracha P et al 2015 RSC Adv. 538130

[22] Park G E, Shin J, Lee D H, Lee T W, Shim H, Cho M J et al 2014 Macromolecules 473747

[23] Back J Y, Kim Y, An T K, Kang M S, Kwon S-K, Park C E et al 2015 Dyes Pigm. 112220

[24] Tsumura A, Koezuka H and Ando T 1986 Appl. Phys. Lett. 49 1210

[25] Horowitz G, Fichou D, Peng X, Xu Z and Garnier F 1989 Solid State Commun. $\mathbf{7 2} 381$

[26] Thompson B C and Fréchet J M J 2008 Angew. Chem. Int. Edit.47 58

[27] Tang M L, Okamoto T and Bao Z 2006 J. Am. Chem. Soc. 128 16002

[28] Minemawari H, Yamada T, Matsui H, Tsutsumi J Y, Haas S, Chiba R et al 2011 Nature $\mathbf{4 7 5} 364$

[29] Pethig R and Morgan K 1967 Nature 214266

[30] Jung K H, Bae S Y, Kim K H, Cho M J, Lee K, Kim Z H et al 2009 Chem. Commun. https://doi.org/10.1039/b911780f5290

[31] Chung D S, Park J W, Park J-H, Moon D, Kim G H, Lee H-S et al 2010 J. Mater. Chem. 20524

[32] Horowitz G and Hajlaoui M E 2000 Adv. Mater. 121046

[33] Guo M, He R, Dai Y, Shen W, Li M, Zhu C et al 2012 J. Phys. Chem. C 1169166

[34] Irfan A, Al-Sehemi A G and Muhammad S 2014 Synth. Met. 19027

[35] Irfan A, Chaudhry A R, Al-Sehemi A G, Sultan Al-Asiri M, Muhammad S and Kalam A 2016 J. Saudi Chem. Soc. 20 336

[36] Irfan A, Chaudhry A R, Muhammad S and Al-Sehemi A G 2017 J. Mol. Graph. Modell. 75209

[37] Irfan A, Cui R, Zhang J and Nadeem M 2010 Aust. J. Chem. 631283

[38] Kohn W, Becke A D and Parr R G 1996 J. Phys. Chem. 100 12974

[39] Becke A D 1993 J. Chem. Phys. 985648

[40] Irfan A, Kalam A, Chaudhry A R, Al-Sehemi A G and Muhammad S 2017 Optik 132101

[41] Irfan A, Al-Sehemi A G, Chaudhry A R and Muhammad S 2017 Optik 138349

[42] Irfan A and Mahmood A 2018 J. Clust. Sci. 29359

[43] Irfan A, Assiri M and Al-Sehemi A G 2018 Org. Electron. 57 211

[44] Irfan A and Abbas G 2018 Z. Naturforsch. A 73337

[45] Sánchez-Carrera R S, Coropceanu V, da Silva Filho D A, Friedlein R, Osikowicz W, Murdey R et al 2006 J. Phys. Chem. B 11018904

[46] Lee C, Yang W and Parr R G 1988 Phys. Rev. B 37785

[47] Petersson G A, Bennett A, Tensfeldt T G, Al-Laham M A, Shirley W A and Mantzaris J 1988 J. Chem. Phys. 892193

[48] Furche F and Ahlrichs R 2002 J. Chem. Phys. 1177433

[49] Zhang C, Liang W, Chen H, Chen Y, Wei Z and Wu Y 2008 J. Mol. Struct. (TheoChem) $\mathbf{8 6 2} 98$

[50] Dufresne S, Hanan G S and Skene W G 2007 J. Phys. Chem. B 11111407

[51] Chaudhry A R, Ahmed R, Irfan A, Shaari A and Al-Sehemi A G 2013 Mater. Chem. Phys. 138468 
[52] Marcus R A and Sutin N 1985 Biochim. Biophys. Acta (BBA) Rev. Bioenerg. 811265

[53] Tsiper E V, Soos Z G, Gao W and Kahn A 2002 Chem. Phys. Lett. 36047

[54] Brédas J L, Calbert J P, da Silva Filho D A and Cornil J 2002 Proc. Natl. Acad. Sci. USA 995804

[55] Frisch M J, Trucks G W, Schlegel H B, Scuseria G E, Robb M A, Cheeseman J R et al 2016 Gaussian

[56] http://www2.chemistry.msu.edu/faculty/harrison/cem483/ work_functions.pdf
[57] Marcus R A 1993 Rev. Mod. Phys. 65599

[58] Irfan A, Chaudhry A R, Al-Sehemi A G, Sultan Al-Asiri M, Muhammad S and Kalam A 2014 J. Saudi Chem. Soc, https:// doi.org/10.1016/j.jscs.2014.09.009

[59] Gruhn N E, da Silva Filho D A, Bill T G, Malagoli M, Coropceanu V, Kahn A et al 2002 J. Am. Chem. Soc. 1247918

[60] Bromley S T, Mas-Torrent M, Hadley P and Rovira C $2004 \mathrm{~J}$. Am. Chem. Soc. 1266544

[61] Irfan A, Cui R, Zhang J and Hao L 2009 Chem. Phys. 364 39 